\title{
Increased serum levels of interleukin- 10 predict poor prognosis in extranodal natural killer/T-cell lymphoma patients receiving asparaginase-based chemotherapy
}

\author{
This article was published in the following Dove Press journal: \\ OncoTargets and Therapy \\ 14 September 2015 \\ Number of times this article has been viewed
}

\author{
Hua Wang ${ }^{1-3, *}$ \\ Liang Wang ${ }^{1-3, *}$ \\ Zhijun Wuxiao ${ }^{4, *}$ \\ HuiQiang Huang 5 \\ WenQi Jiang 5 \\ ZhiMing $\mathrm{Li}^{5}$ \\ Yue Lu ${ }^{1-3}$ \\ ZhongJun $\mathrm{Xia}^{\mathrm{l}-3}$ \\ 'Department of Hematological \\ Oncology, Sun Yat-Sen University \\ Cancer Center, Guangzhou, People's \\ Republic of China; ${ }^{2}$ State Key \\ Laboratory of Oncology in South \\ China, Guangzhou, People's Republic \\ of China; ${ }^{3}$ Collaborative Innovation \\ Center for Cancer Medicine, \\ Guangzhou, People's Republic of \\ China; ${ }^{4}$ Department of Hematology \\ \& Oncology, The Affiliated Hospital, \\ Hainan Medical College, Haikou, \\ Hainan, People's Republic of China; \\ ${ }^{5}$ Department of Medical Oncology, \\ Sun Yat-Sen University Cancer Center, \\ Guangzhou, People's Republic of \\ China \\ *These authors contributed equally \\ to this work
}

Correspondence: ZhongJun Xia

Department of Hematological Oncology, Sun Yat-Sen University Cancer Center; State Key Laboratory of Oncology in South China; Collaborative Innovation

Center for Cancer Medicine, 65I Dong

Feng Road East, Guangzhou 510060,

People's Republic of China

Tel +86 2087342462

Fax +86 2087342462

Email zhongjunxia_15@sina.com

\begin{abstract}
There are currently no prognostic biomarkers for extranodal natural killer/T-cell lymphoma (ENKTL) patients receiving asparaginase-based chemotherapy. Interleukin-10 (IL-10) is a pleiotropic cytokine that is involved in the stimulation and suppression of immune responses and influences the prognosis of different subtypes of lymphoma. We retrospectively analyzed 98 newly diagnosed patients with ENKTL receiving asparaginase-based chemotherapy. Baseline serum IL-10 levels were tested with sandwich enzyme-linked immunosorbent assays. Patients with high IL-10 ( $\geq 12.28 \mathrm{pg} / \mathrm{mL})$ at diagnosis tended to have more adverse clinical features. Patients with low IL-10 $(<12.28 \mathrm{pg} / \mathrm{mL})$ at diagnosis had better progression-free survival (PFS) $(P<0.001)$ and overall survival (OS) $(P<0.001)$. Multivariate analysis revealed that baseline serum IL-10 level $\geq 12.28 \mathrm{pg} / \mathrm{mL}$, stage III/IV, elevated serum ferritin, and elevated serum Epstein-Barr virus DNA level at diagnosis were four adverse factors for PFS and OS. Based on these four independent prediction factors, we divided the patients into different subgroups as follows: group 1, no adverse factors; group 2, one factor; group 3, two factors; and group 4, three or four factors. Furthermore, significant differences in PFS and OS were found between the groups. Our results suggest that pretreatment serum IL-10 is a novel, powerful predictor of prognosis for ENKTL patients receiving asparaginase-based chemotherapy, which suggests a role for IL-10 in the pathogenesis of this disease and offers new insight into potential therapeutic strategies.
\end{abstract}

Keywords: ELISA, extranodal NK/T-cell lymphoma, Serum IL-10

\section{Introduction}

Extranodal natural killer (NK)/T-cell lymphoma (ENKTL), nasal type, is relatively more common in Asia and Latin America than in Western countries ${ }^{1,2}$ and accounts for $5 \%-10 \%$ of all malignant lymphomas in People's Republic of China. ${ }^{3}$ Clinically, two major clinical prognostic models are applied in NK/T-cell lymphoma: the International Prognostic Index (IPI) and the Korean Prognostic Index (KPI). The IPI has been widely used for predicting prognosis and selecting therapeutic options in patients with aggressive non-Hodgkin's lymphoma. However, IPI value has not been confirmed in ENKTL because almost $60 \%$ of the patients with ENKTL belong to the low-IPI-risk group (scores of $0-1$ ), in which significant heterogeneity exists. The KPI was developed in the era of anthracycline-based chemotherapy, ${ }^{2}$ which could not be repeated in some studies, ${ }^{4}$ particularly in the era of asparaginase-based chemotherapy. ${ }^{5}$ Multiple clinical trials confirm that asparaginase-based chemotherapy produces improved remission 
and better survival than anthracycline-based chemotherapy in ENKTL. ${ }^{5,6}$ Moreover, these prognostic models are also primarily based on pretreatment clinical characteristics. Therefore, new prognostic biomarkers are needed for ENKTL patients receiving asparaginase-based chemotherapy. It is clear that serum immune markers are usually important regulatory factors in tumor behaviors. Recently, some helpful biomarkers have been discovered to be independent prognostic factors in ENKTL, such as plasma Epstein-Barr virus (EBV) DNA load, ${ }^{7}$ serum ferritin, ${ }^{8}$ and soluble interleukin 2 receptor (sIL2R)a levels at diagnosis. ${ }^{9}$

Interleukin-10 (IL-10) is a pleiotropic cytokine involved in the stimulation and suppression of immune response. ${ }^{10}$ IL-10 has been proven to inhibit various immune functions, such as macrophage activation, cytokine production, and antigen presentation. ${ }^{11}$ Moreover, IL-10 has been shown to play a key role in initiating and promoting certain types of malignancies. ${ }^{12}$ With respect to the clinical significance of IL-10 in lymphoma, previous studies have reported that IL-10 gene polymorphism influences the treatment response and prognosis of T-cell non-Hodgkin lymphomas. ${ }^{13}$ Furthermore, experimental studies have suggested that IL-10 plays an important role in the regulation of tumorigenicity and induction of chemoresistance in T-cell lymphoma. ${ }^{14,15}$ Accordingly, we hypothesized that pretreatment serum levels of IL-10 may be associated with the progression and prognosis of ENKTL. The present study was designed to investigate the clinical usefulness of serum levels of IL-10 as new tumor markers for patients with ENKTL.

\section{Patients and methods Ethics statement}

Written informed consent for patients' tissue samples and other medical information to be stored in our hospital database were obtained from all patients, and we also obtained separate consent for use of research. This study was approved by the Institutional Review Board of the National Cancer Institute, as well as ethics committees of Sun Yat-Sen University Cancer Center and Affiliated Hospital of Hainan Medical College. The study was performed in accordance with the Declaration of Helsinki and the institutional guidelines of the local ethics committee.

\section{Patient selection}

A total of 98 patients with histologically proven diagnosis of ENKTL, nasal type, were selected from June 2008 to August 2014 at the Sun Yat-Sen University Cancer Center (Guangzhou, People's Republic of China) and Affiliated
Hospital of Hainan Medical College (Haikou, Hainan, People's Republic of China). Central pathological review was performed. Patient selection was based on the following criteria: 1) histologically confirmed diagnosis of ENKTL based on the World Health Organization "classification of tumours of haematopoietic and lymphoid tissues"; 16 2) NK/T-cell type proven in the tests of CD3, CD56, and cytotoxic molecules (TIA-1, granzyme B, and perforin) detected by immunohistochemistry, EBV (EBER) and also detected by in situ hybridization; 3) no previous malignant tumor or second primary tumor; 4) previously untreated; and 5) adequate clinical information and follow-up data. Patients were excluded if EBV in situ hybridization was negative, and other subtypes of non-Hodgkin lymphoma and extra upper-aerodigestive-tract NK/T-cell lymphoma were not included. Clinical data of patients were obtained from the hospital discharge database, mortality registry, and electronic medical records, which contained the following information: patient demographics, physical examination, Eastern Cooperative Oncology Group (ECOG) performance status (PS), B symptoms (including unexplained fever with temperature above $38^{\circ} \mathrm{C}$, night sweating, or weight loss of more than $10 \%$ within 6 months), primary site, involved sites, involvement of regional lymph nodes, serum lactate dehydrogenase (LDH), serum EBV DNA copy number, serum ferritin level, serum sIL2R level, Ann Arbor stage, IPI (age, stage, LDH, extranodal sites, and PS), and KPI (adverse factors: stage $>2$, LDH greater than normal, presence of B symptoms, and involvement of regional lymph nodes).

\section{Treatment}

Patients received treatment strategies as follows: 1) patients with early-stage ENKTL received chemotherapy followed by involved-field radiotherapy (IFRT); and 2) patients with advanced-stage ENKTL received chemotherapy alone. The chemotherapy regimens were: 1) gemcitabine, oxaliplatin, and L-asparaginase (GELOX); ${ }^{6,17}$ and 2) gemcitabine, oxaliplatin, and pegaspargase (P-Gemox). ${ }^{6,17}$ After four to six cycles of chemotherapy, patients received IFRT. IFRT of 36-60 Gy was delivered in daily fractions of 1.8-2.0 Gy (five fractions per week). Computed tomography scan or fludeoxyglucose $(18 \mathrm{~F})$ positron emission tomography/computed tomography was performed to investigate the curative effect after every two courses of chemotherapy. Treatment response was assessed according to the International Working Group recommendations for response criteria for non-Hodgkin's lymphoma. ${ }^{18}$ Routine follow-up imaging analyses, as well as hematology and biochemistry of blood serum tests, were performed every 3 months for the first 2 years, then every 
6 months for the next 3 years, and yearly thereafter or whenever clinically indicated.

\section{Enzyme-linked immunosorbent assay}

The level of serum IL-10 was tested with sandwich enzymelinked immunosorbent assay (ELISA) kits (R\&D Systems, Inc., Minneapolis, MN, USA). All the samples of venous blood were collected from patients at diagnosis as well as from fourteen healthy subjects. Serum was collected by centrifuging the blood samples and was stored at $-80^{\circ} \mathrm{C}$ until further assay. A routine ELISA method was used to carry out the test according to the manufacturer's protocol. Briefly, standards and samples were added to a microplate, which had been precoated with a mouse monoclonal antibody specific to IL-10. Any unbound antibody or enzyme reagent was removed by washing with wash buffer. Then, a substrate solution was added into each well; color development was terminated by stop solution; and the resulting absorbance was read at $450 \mathrm{~nm}$ using a spectrophotometer (Tecan, Mannedorf, Switzerland). IL-10 concentrations were determined based on a standard curve, which was established using the recombinant IL-10 protein. Each sample was analyzed in triplicate and the results were averaged.

\section{Statistical analysis}

Serum IL-10 concentration was presented as median (minimum, maximum). Differences between the two groups were compared by Mann-Whitney $U$-test or chi-square test. The cutoff concentration for serum IL-10 in predicting survival was determined using receiver operating characteristic (ROC) curve analysis. Overall survival (OS) was measured from the date of diagnosis to the date of death or last follow-up visit. Progression-free survival (PFS) was calculated from the date of diagnosis to the date of disease progression, relapse, death, or last follow-up visit. The Kaplan-Meier method was used to calculate the probability of survival, and survival curves were tested using log-rank test. Univariate and multivariate analyses were performed using Cox proportional hazards model. Two-sided $P$-values $<0.05$ were considered statistically significant. Statistical analysis was performed with SPSS software (SPSS Standard version 19.0; IBM Corporation, Armonk, NY, USA).

\section{Results}

\section{Patient characteristics}

In total, 98 patients (64 male, 34 female; median age 44 years) met the inclusion criteria. The clinical characteristics of the 98 patients are listed in Table 1. Most patients
(88 cases, $89.8 \%$ ) had a favorable PS (ECOG PS 0-1), and B symptoms occurred in 40 patients $(40.8 \%)$. Elevated LDH levels were observed for 30 cases $(30.6 \%)$. The median serum ferritin level at diagnosis was $315 \mathrm{ng} / \mathrm{mL}$ (range $105-57,850 \mathrm{ng} / \mathrm{mL}$ ). Fifty patients (51.0\%) presented regional lymph node involvement. A majority of the patients (77 cases, 78.6\%) had Ann Arbor stage I-II disease. According to the IPI, most patients ( 76 cases, $77.6 \%$ ) were categorized as low/low-to-intermediate risk (IPI $=0-1)$ and 22 patients $(22.4 \%)$ were classified as intermediate-to-high/ high risk (IPI $=2-5$ ). The number of patients with KPI $=0-1$ (58 cases, 59.2\%) was significantly higher than those with KPI $=2-4$ (40 cases, $40.8 \%)$.

Table I Clinical characteristics of patients at diagnosis

\begin{tabular}{|c|c|c|}
\hline Characteristics & $\begin{array}{l}\text { Number of } \\
\text { patients }(\mathrm{N}=98)\end{array}$ & $\%$ \\
\hline $\begin{array}{l}\text { Age at diagnosis (years), } \\
\text { median (range) }\end{array}$ & $44(17-76)$ & \\
\hline$\leq 60$ & 79 & 80.6 \\
\hline$>60$ & 19 & 19.4 \\
\hline \multicolumn{3}{|l|}{$\operatorname{Sex}(n)$} \\
\hline Male & 64 & 65.3 \\
\hline Female & 34 & 34.7 \\
\hline \multicolumn{3}{|l|}{ ECOG PS } \\
\hline $0-1$ & 88 & 89.8 \\
\hline$\geq 2$ & 10 & 10.2 \\
\hline B symptoms & 40 & 40.8 \\
\hline $\mathrm{LDH}>245 \mathrm{U} / \mathrm{L}$ & 30 & 30.6 \\
\hline EBV DNA, median (range) & $7,650(0-50,000,000)$ & \\
\hline $\begin{array}{l}\text { Ferritin levels, median, } \\
\mathrm{ng} / \mathrm{mL} \text { (range) }\end{array}$ & $315(105-57,850)$ & \\
\hline $\begin{array}{l}\text { sIL2R levels, median, ng/L } \\
\text { (range) }\end{array}$ & $2,650(857-8,505)$ & \\
\hline LN involvement, ng/L & 50 & 51.0 \\
\hline Ann Arbor stage & 25 & 26.0 \\
\hline I, II & 77 & 78.6 \\
\hline III, IV & 21 & 21.4 \\
\hline \multicolumn{3}{|l|}{ IPI score } \\
\hline $0-1$ & 76 & 77.6 \\
\hline$\geq 2$ & 22 & 22.4 \\
\hline \multicolumn{3}{|l|}{ KPI score } \\
\hline $0-1$ & 58 & 59.2 \\
\hline$\geq 2$ & 40 & 40.8 \\
\hline \multicolumn{3}{|l|}{ Chemotherapy regimens } \\
\hline GELOX & 28 & 28.6 \\
\hline P-Gemox & 70 & 71.4 \\
\hline \multicolumn{3}{|l|}{ Pretreatment serum IL-10 } \\
\hline $\begin{array}{l}\text { Median concentration, } \\
\mathrm{pg} / \mathrm{mL} \text { (range) }\end{array}$ & $10.15(1.71-64.56)$ & \\
\hline
\end{tabular}

Abbreviations: EBV DNA, Epstein-Barr virus DNA; ECOG PS, Eastern Cooperative Oncology Group performance status; GELOX, gemcitabine, oxaliplatin, and L-asparaginase; IPI, International Prognostic Index; KPI, Korean Prognostic Index; LDH, lactate dehydrogenase; LN, local lymph node; P-Gemox, gemcitabine, oxaliplatin, and pegaspargase; sIL2R, soluble interleukin-2 receptor. 


\section{Serum IL- I 0 content at baseline and correlation between serum IL- 10 levels and clinical features}

The median concentration of serum IL-10 for all patients was $10.15 \mathrm{pg} / \mathrm{mL}$ (range $1.71-64.56 \mathrm{pg} / \mathrm{mL}$ ) with a mean of $11.96 \mathrm{pg} / \mathrm{mL}$. Serum IL-10 was measured in 14 healthy volunteers, and the median concentration was $0.72 \mathrm{pg} / \mathrm{mL}$ (range $0-1.24 \mathrm{pg} / \mathrm{mL}$ ), which was significantly lower compared with that in ENKTL patients $(P<0.001)$. ROC curve analysis for the optimal cutoff point of serum IL-10 in prediction of survival was performed. The most discriminative cutoff concentration of serum IL-10 was $12.28 \mathrm{pg} / \mathrm{mL}$ with an area under the curve value of 0.808 . The sensitivity and specificity were $75.0 \%$ and $74.3 \%$, respectively. According to the results of ROC analysis, we used the IL-10 level $\geq 12.28 \mathrm{pg} / \mathrm{mL}$ as the cutoff value in the present study. In terms of this cutoff value, 59 patients $(60.2 \%)$ were categorized into the low IL-10 group $(<12.28 \mathrm{pg} / \mathrm{mL})$ and 39 patients $(39.8 \%)$ were classed into the high IL-10 group ( $\geq 12.28 \mathrm{pg} / \mathrm{mL})$. As shown in Table 2, the serum IL-10 level was significantly higher in patients with B symptoms, elevated LDH levels, elevated ferritin levels, lymph node involvement, etc. However, there was no significant correlation between serum IL-10 level and age, sex, ECOG PS, and Ann Arbor stage. Similarly, IL-10 levels in GELOX and P-Gemox groups had no significant difference.

\section{Treatment modalities and response}

All 98 patients received chemotherapy; 28 patients received the GELOX regimen whereas the other 70 patients received the P-Gemox regimen. There were no significant differences in the rates of clinicopathological features between the two chemotherapy regimens, as shown in Table S1. The primary treatment modalities were as follows: 1) 77 cases (78.6\%) received chemotherapy followed by radiotherapy; and 2) 21 cases $(21.4 \%)$ received chemotherapy alone. The treatment details and responses are listed in Table 3. No significant difference was found in the treatment modalities between the patients displaying IL-10 levels $<12.28 \mathrm{pg} / \mathrm{mL}$ and patients with IL-10 levels $\geq 12.28 \mathrm{pg} / \mathrm{mL}(P=0.804)$. After the initial treatment involving asparaginase-based chemotherapy, 63 of the 98 treated patients (64.3\%) achieved complete remission (CR). The CR rate for initial treatment in the low IL-10 group was significantly higher than that in the high IL-10 group (72.9\% vs 51.3\%, respectively, $P=0.034$ ).

\section{Survival}

At a median follow-up of 32 months (range 2-79 months), the 3 -year PFS and OS rates for all 98 patients were 57.0\% (95\%
Table 2 Correlation of serum IL- I 0 level with clinicopathological features in ENKTL patients

\begin{tabular}{|c|c|c|}
\hline Characteristics & $\begin{array}{l}\text { Median concentration, } \\
\mathrm{pg} / \mathrm{mL} \text { (range) }\end{array}$ & $P$-value \\
\hline Age, years & & 0.968 \\
\hline$\leq 60$ & $10.33(1.7 \mid-64.56)$ & \\
\hline$>60$ & 9.15 (3.94-28.17) & \\
\hline Sex & & 0.684 \\
\hline Male & $9.89(2.72-28.85)$ & \\
\hline Female & $12.09(1.7 \mid-64.56)$ & \\
\hline ECOG PS & & 0.425 \\
\hline $0-1$ & $9.89(1.71-64.56)$ & \\
\hline$\geq 2$ & $11.82(7.93-19.48)$ & \\
\hline B symptoms & & 0.004 \\
\hline Absent & $9.43(1.71-28.17)$ & \\
\hline Present & $13.03(2.87-64.56)$ & \\
\hline Serum LDH & & 0.004 \\
\hline Normal & $9.32(2.72-28.17)$ & \\
\hline More than normal & $|2.9|(1.7 \mid-64.56)$ & \\
\hline EBV DNA ${ }^{\mathrm{a}}$, copies/mL & & 0.001 \\
\hline$<7,650$ & $9.12(1.71-16.66)$ & \\
\hline$\geq 7,650$ & $|2.9|(2.72-64.56)$ & \\
\hline Ferritin levels & & 0.004 \\
\hline$\leq 315 \mathrm{ng} / \mathrm{mL}$ & $8.56(1.71-25.43)$ & \\
\hline$>315 \mathrm{ng} / \mathrm{mL}$ & $12.35(3.34-64.56)$ & \\
\hline sIL2R levels & & 0.023 \\
\hline$\leq 2,650 \mathrm{ng} / \mathrm{L}$ & $9.01(1.71-64.56)$ & \\
\hline$>2,650 \mathrm{ng} / \mathrm{L}$ & $12.10(3.34-28.17)$ & \\
\hline LN involvement & & 0.031 \\
\hline Absent & $9.14(1.71-28.17)$ & \\
\hline Present & $12.3(2.87-64.56)$ & \\
\hline Ann Arbor stage & & 0.603 \\
\hline $\mid / / I$ & $10.33(1.7 \mid-64.56)$ & \\
\hline $\mathrm{III} / \mathrm{IV}$ & $8.85(2.87-16.59)$ & \\
\hline IPI score & & 0.327 \\
\hline $0-1$ & $9.82(1.71-64.56)$ & \\
\hline $2-5$ & $12.35(7.26-23.63)$ & \\
\hline KPI score & & 0.003 \\
\hline $0-1$ & $9.19(1.7 \mid-28.17)$ & \\
\hline $2-4$ & $12.87(2.87-64.56)$ & \\
\hline Chemotherapy regimens & & 0.801 \\
\hline GELOX & $10.10(1.71-28.85)$ & \\
\hline P-Gemox & $10.15(2.72-64.56)$ & \\
\hline
\end{tabular}

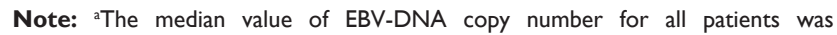
7,650 copies $/ \mathrm{mL}$.

Abbreviations: EBV DNA, Epstein-Barr virus DNA; ECOG PS, Eastern Cooperative Oncology Group performance status; ENKTL, extranodal natural killer/T-cell lymphoma; GELOX, gemcitabine, oxaliplatin, and L-asparaginase; IPI, International Prognostic Index; KPI, Korean Prognostic Index; LDH, lactate dehydrogenase; LN, lymph node; P-Gemox, gemcitabine, oxaliplatin, and pegaspargase; sIL2R, soluble interleukin-2 receptor; IL-10, interleukin-10.

Table 3 Primary treatment and response in patients with extranodal natural killer/T-cell lymphoma

\begin{tabular}{llll}
\hline Treatment & $\begin{array}{l}\text { Low IL-10 } \\
\text { group, } \mathbf{n}(\%)\end{array}$ & $\begin{array}{l}\text { High IL-10 } \\
\text { group, n (\%) }\end{array}$ & P-value \\
\hline Treatment modalities & & & 0.804 \\
CT followed by RT & $47(79.7)$ & $30(76.9)$ & \\
CT alone & $12(20.3)$ & $9(23.1)$ & \\
Complete remission & $43(72.9)$ & $20(51.3)$ & 0.034 \\
\hline
\end{tabular}

Abbreviations: $\mathrm{CT}$, chemotherapy; RT, radiotherapy; IL-10, interleukin- 10 . 


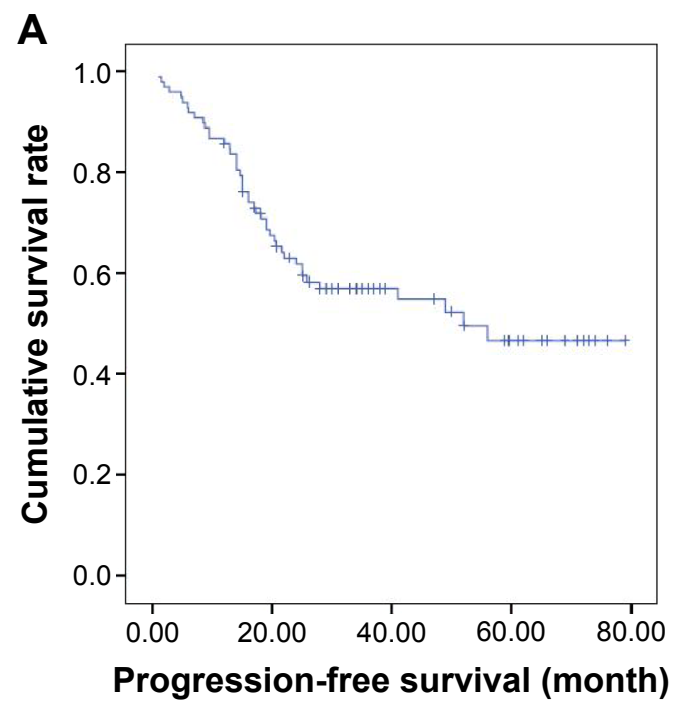

Figure I Survival for all patients.

Notes: (A) Progression-free survival. (B) Overall survival.

confidence interval 47.0-67.0) and 65.2\% (95\% confidence interval 55.4-75.0), respectively (Figure 1). Patients in the low IL-10 group had significantly better survival (3-year PFS rate: $72.1 \%$ vs $33.7 \%, P<0.001$ [Figure $2 \mathrm{~A}$ ]; 3 -year OS rate: $79.1 \%$ vs $44.3 \%, P<0.001$ [Figure $2 \mathrm{~B}$ ]). In the patients receiving chemotherapy alone ( $\mathrm{n}=21,21.4 \%)$, elevated serum IL-10 levels resulted in shorter PFS and OS $(P=0.035$ and $P=0.021$, respectively) and were also associated with inferior PFS and OS ( $P<0.001$ and $P<0.001$, respectively) in the patients who received chemotherapy followed by radiotherapy $(\mathrm{n}=77$,

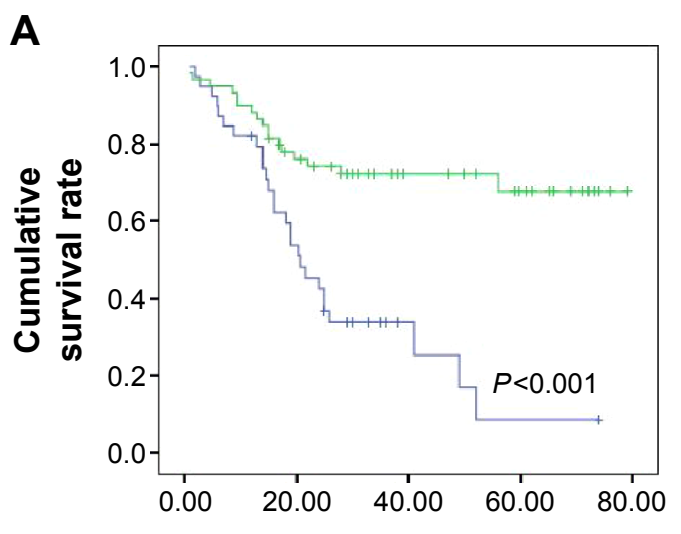

Progression-free survival (month)

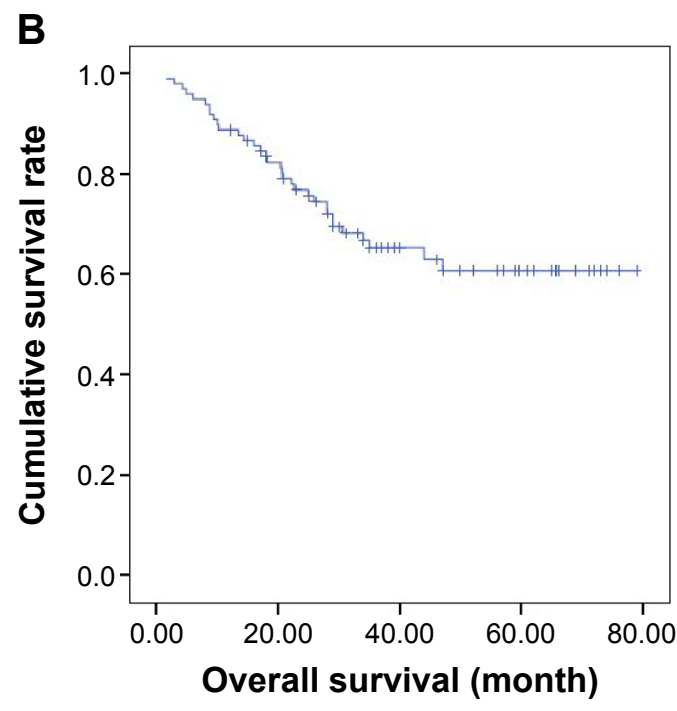

78.6\%). Significant survival differences were found between the patients who gained $\mathrm{CR}$ after chemotherapy and those without CR $(P<0.001$ and $P<0.001$, respectively). Serum IL-10 levels can divide the patients in the IPI $0-1$ subgroup $(\mathrm{n}=76,77.6 \%)$ into two groups with significant differences in PFS and $\mathrm{OS}(P<0.001$ and $P<0.001$, respectively; Figure $3 \mathrm{~A}$ and B). Similarly, for patients in the KPI $0-1$ subgroup $(\mathrm{n}=58$, $59.2 \%$ ), elevated serum IL-10 levels at diagnosis also helped to differentiate patients with different prognoses $(P=0.033$ and $P=0.010$, respectively; Figure $3 \mathrm{C}$ and $\mathrm{D}$ ).

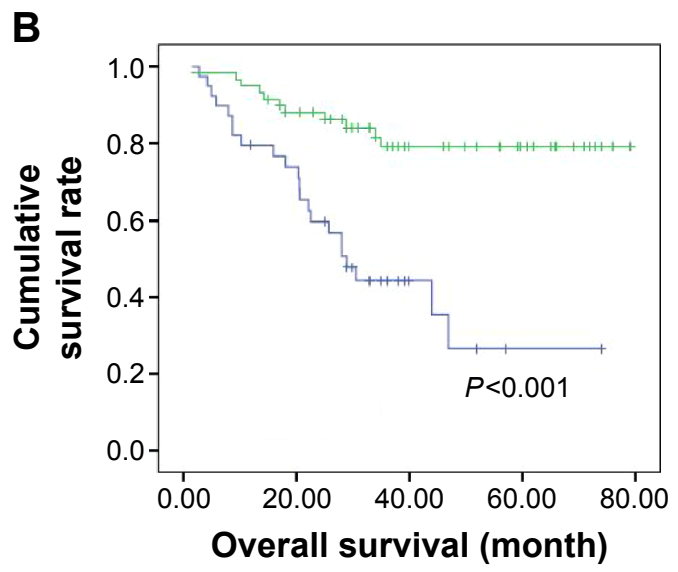

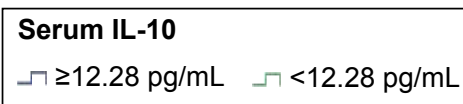

Figure 2 Survival outcome of patients based on serum IL- 10 level.

Notes: (A) Progression-free survival of patients according to serum IL- 10 level ( $<12.28 \mathrm{pg} / \mathrm{mL}$ vs $\geq 12.28 \mathrm{pg} / \mathrm{mL}$ ). (B) Overall survival of patients according to baseline IL- 10 level $(<12.28 \mathrm{pg} / \mathrm{mL}$ vs $\geq 12.28 \mathrm{pg} / \mathrm{mL})$.

Abbreviation: IL-10, interleukin-10. 

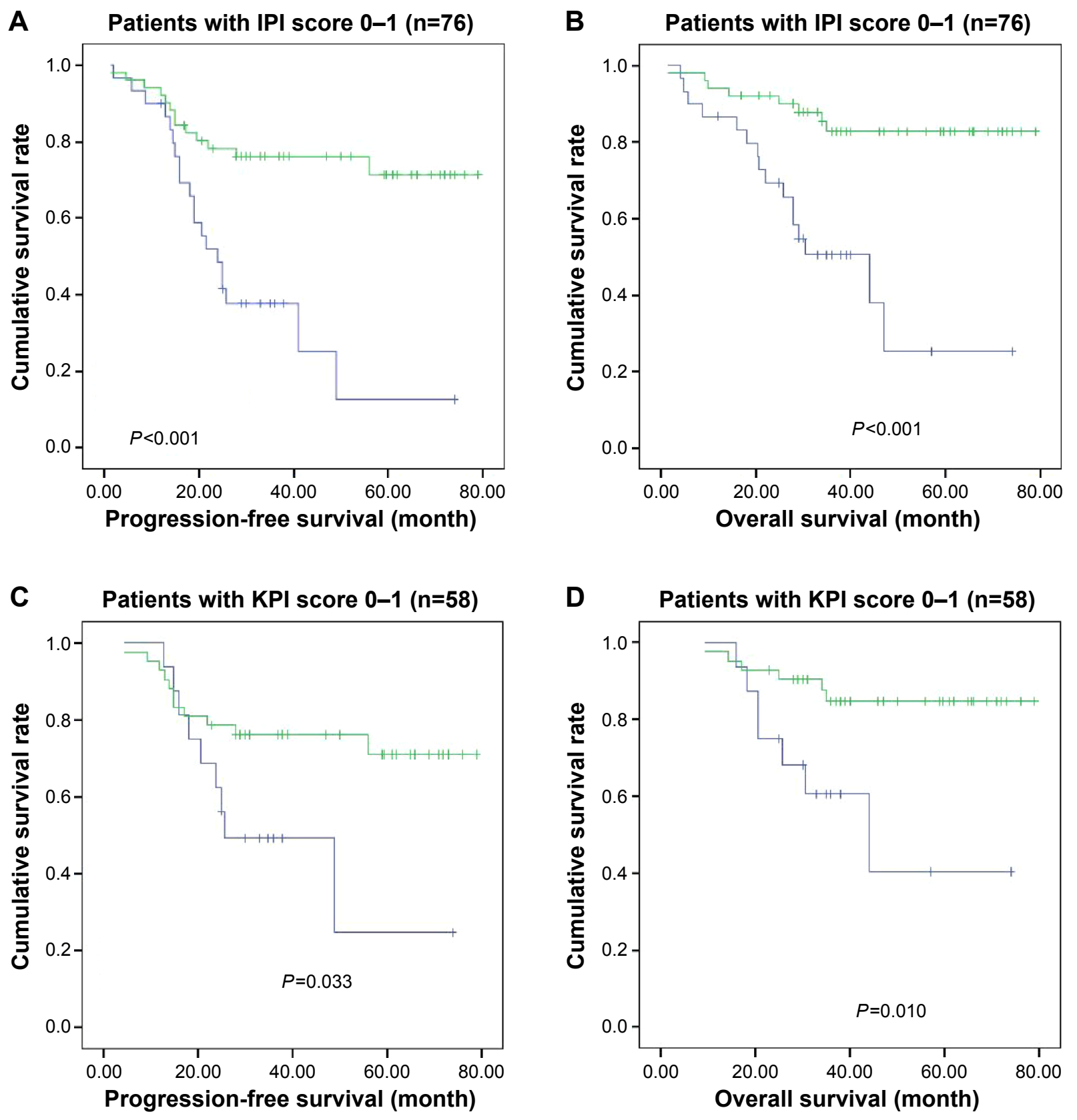

Serum IL-10
$-\neg \geq 12.28 \mathrm{pg} / \mathrm{mL} \quad-<12.28 \mathrm{pg} / \mathrm{mL}$

Figure 3 PFS and OS according to serum IL- 10 level $(<12.28 \mathrm{pg} / \mathrm{mL}$ vs $\geq 12.28 \mathrm{pg} / \mathrm{mL})$ at diagnosis in patients with extranodal natural killer/T-cell lymphoma, nasal type. Notes: Kaplan-Meier plots of (A) PFS and (B) OS for subgroups with low IPI score of 0-I; Kaplan-Meier plots of (C) PFS and (D) OS for subgroups with low KPI score of $0-1$.

Abbreviations: IPI, International Prognostic Index; KPI, Korean Prognostic Index; OS, overall survival; PFS, progression-free survival; IL-I0, interleukin-I0.

\section{Prognostic factors}

Table 4 displays the results of the univariate and multivariate analyses for the potential predictors of PFS and OS. Clinical factors that were statistically significant predictors of OS and PFS were included in the multivariate analysis. We did not include IPI and KPI values in the multivariate analysis because of their overlap with several other clinical variables. Multivariate analysis using the forward conditional Cox region model revealed that serum $\mathrm{IL}-10$ level $\geq 12.28 \mathrm{pg} / \mathrm{mL}$ at diagnosis, stage III/IV, elevated serum EBV DNA, and 
Table 4 Univariate and multivariate analysis of factors associated with progression-free survival and overall survival of all patients

\begin{tabular}{|c|c|c|c|c|c|c|}
\hline \multirow[t]{3}{*}{ Clinical characteristics } & \multicolumn{3}{|c|}{ Progression-free survival } & \multicolumn{3}{|l|}{ Overall survival } \\
\hline & \multirow{2}{*}{$\begin{array}{l}\text { Univariate analysis } \\
P \text {-value }\end{array}$} & \multicolumn{2}{|c|}{ Multivariate analysis } & \multirow{2}{*}{$\begin{array}{l}\text { Univariate analysis } \\
P \text {-value }\end{array}$} & \multicolumn{2}{|c|}{ Multivariate analysis } \\
\hline & & $\operatorname{RR}(95 \% \mathrm{CI})$ & $P$-value & & $\operatorname{RR}(95 \% \mathrm{Cl})$ & $P$-value \\
\hline Age $>60$ years & 0.358 & & & 0.887 & & \\
\hline Sex, male & 0.921 & & & 0.389 & & \\
\hline ECOG PS $\geq 2$ & 0.285 & & & 0.288 & & \\
\hline B symptoms & 0.043 & & & 0.015 & & \\
\hline Elevated serum LDH & 0.004 & & & 0.001 & & \\
\hline EBV DNA $\geq 7,650$ copies $/ \mathrm{mL}$ & $<0.00 \mathrm{I}$ & $2.62(1.34-5.13)$ & 0.005 & 0.001 & $2.68(1.22-5.88)$ & 0.014 \\
\hline Ferritin levels $>315 \mathrm{ng} / \mathrm{mL}$ & 0.001 & $2.92(1.44-5.94)$ & 0.003 & 0.001 & $2.87(1.25-6.58)$ & 0.013 \\
\hline sIL2R levels $>2,650 \mathrm{ng} / \mathrm{L}$ & 0.027 & & & 0.042 & & \\
\hline LN involvement & 0.021 & & & 0.140 & & \\
\hline Serum IL- $10 \geq 12.28 \mathrm{pg} / \mathrm{mL}$ & $<0.001$ & $2.81(1.44-5.47)$ & 0.002 & $<0.001$ & $3.38(1.57-7.28)$ & 0.002 \\
\hline Ann Arbor stage III, IV & 0.001 & $7.44(3.21-17.24)$ & $<0.001$ & $<0.001$ & $9.70(3.76-25.03)$ & $<0.001$ \\
\hline IPI score $\geq 2$ & $<0.001$ & & & $<0.001$ & & \\
\hline KPI score $\geq 2$ & $<0.001$ & & & $<0.001$ & & \\
\hline
\end{tabular}

Abbreviations: $\mathrm{Cl}$, confidence interval; EBV DNA, Epstein-Barr virus DNA; ECOG PS, Eastern Cooperative Oncology Group performance status; IPI, International Prognostic Index; KPI, Korean Prognostic Index; LDH, lactate dehydrogenase; LN, local lymph node; RR, relative risk; sIL2R, soluble interleukin-2 receptor; IL-I0, interleukin-I0.

elevated ferritin level at diagnosis were four adverse factors for PFS and OS. Based on these four independent prediction factors (serum IL-10, stage III/IV, serum EBV DNA, and serum ferritin) for OS and PFS in the multivariate analysis, we divided the patients into different subgroups as follows: group 1, no adverse factors; group 2, one factor; group 3, two factors; and group 4, three or four factors (Table 5). Furthermore, significant differences in PFS and OS were found between group 1 and group 2 (PFS: $P=0.045$; OS: $P=0.048$ ); between group 2 and group 3 (PFS: $P=0.019$; OS: $P=0.045$ ); and between group 3 and group 4 (PFS: $P=0.001$; OS: $P=0.001$ ) (Figure 4).

\section{Discussion}

Previous studies have demonstrated that IL-10 gene polymorphism and increased serum IL-10 levels influence the prognosis of various subtypes of lymphoma including diffuse large B-cell lymphoma, peripheral T-cell lymphoma, and Hodgkin lymphomas, etc. ${ }^{13,19-22}$ However, little is known about the prognostic role of IL-10 in ENKTL. In this present study,

Table 5 PFS and OS of 96 patients based on the new risk groups

\begin{tabular}{lllll}
\hline Risk group & $\begin{array}{l}\text { Number of } \\
\text { adverse factors }^{\mathbf{a}}\end{array}$ & $\begin{array}{l}\text { Number } \\
\text { of patients }\end{array}$ & $\begin{array}{l}\text { 3-year PFS } \\
\text { rate (\%) }\end{array}$ & $\begin{array}{l}\text { 3-year OS } \\
\text { rate (\%) }\end{array}$ \\
\hline Group I & 0 & 17 & 94.1 & 100.0 \\
Group 2 & 1 & 32 & 81.2 & 84.0 \\
Group 3 & 2 & 24 & 46.4 & 54.6 \\
Group 4 & 3 or 4 & 25 & 9.1 & 18.1 \\
\hline
\end{tabular}

Notes: aAdverse factors: EBV DNA $\geq 7,650$ copies $/ \mathrm{mL}$, serum IL- $10 \geq 12.28 \mathrm{pg} / \mathrm{mL}$, Ann Arbor stage III, IV, ferritin levels $>315 \mathrm{ng} / \mathrm{mL}$.

Abbreviations: OS, overall survival; PFS, progression-free survival; EBV DNA, Epstein-Barr virus DNA; IL-I0, interleukin-10. we found that the serum levels of IL-10 in ENKTL patients were significantly higher than those in normal healthy people. In patients with ENKTL, the concentrations of serum IL-10 were found to be closely associated with clinicopathological features, such as B symptoms, elevated LDH levels, elevated ferritin levels, lymph node involvement, etc. In addition, elevated serum concentration of IL-10 significantly correlated with poor responses to chemoradiotherapy or chemotherapy. According to the Cox regression model that included serum IL-10 level, B symptoms, elevated serum LDH, serum EBV DNA, elevated serum ferritin levels, stage III/IV, etc, the result showed that serum IL-10 was an independent prognostic factor for both PFS and OS. This is the first study with a relatively large sample to report a prognostic biomarker in ENKTL patients receiving asparaginase-based chemotherapy. Similarly, we found that IL-10 level correlated with adverse clinical features of ENKTL, including B symptoms and elevated LDH levels, and was a significant independent prognostic factor in the patients of ENKTL treated with other chemotherapy regimens (such as cyclophosphamide, doxorubicin, vincristine, and prednisone as well as etoposide, vincristine, doxorubicin, cyclophosphamide and prednisone), which are almost never used anymore as first-line therapy in clinical practice because of their significantly inferior outcome in comparison with GELOX. ${ }^{23}$

In the present study, we detected the serum levels of IL-10 in patients with ENKTL and healthy volunteers. We found that the IL-10 levels in ENKTL patients, with a median value of $10.15 \mathrm{pg} / \mathrm{mL}$, were significantly higher compared with those in the healthy controls (median concentration $0.72 \mathrm{pg} / \mathrm{mL}$ ). Although Shen et al reported IL-10 was highly 
A

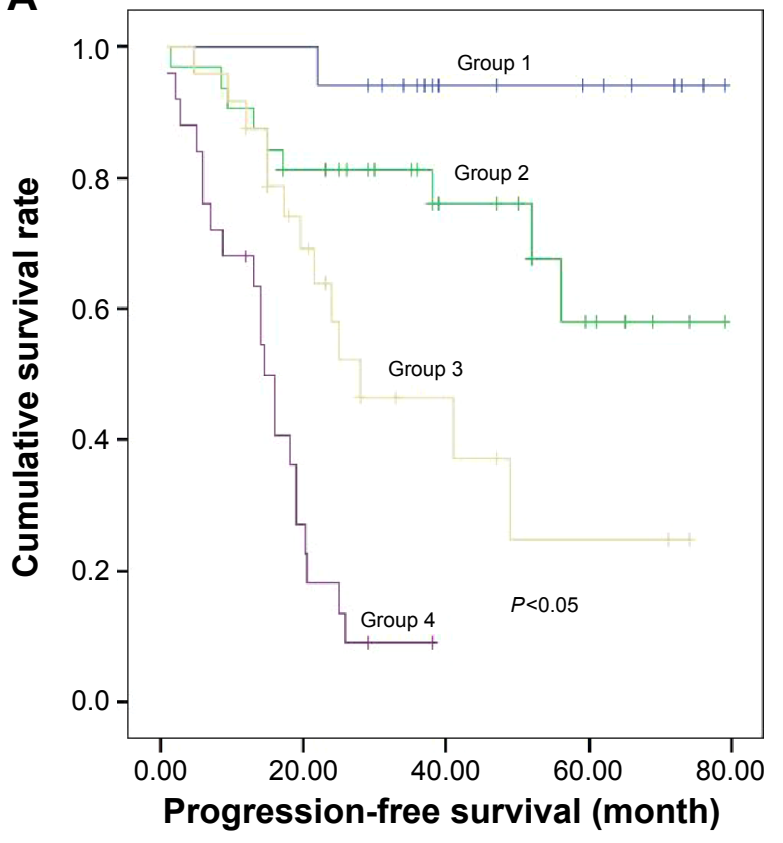

B

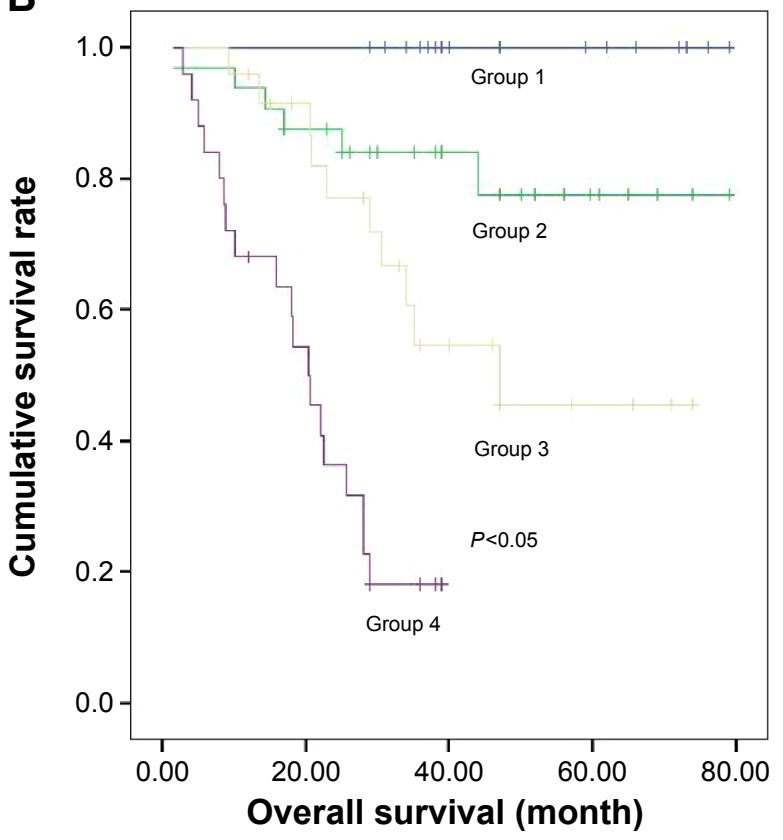

Figure 4 Progression-free survival and overall survival based on the new risk groups in patients with extranodal natural killer/T-cell lymphoma, nasal type. Notes: (A) Progression-free survival and (B) overall survival based on the new risk groups in patients with extranodal natural killer/T-cell lymphoma, nasal type. Group I, no adverse factors; Group 2, one factor; Group 3, two factors; and Group 4, three or four factors.

expressed in nasal NK/T-cell lymphomas, ${ }^{24}$ there is no literature reported regarding serum IL-10 levels in patients with ENKTL. Gupta et al reported the median serum IL-10 level for Diffuse large B-cell lymphoma (DLBCL) patients is $26.0 \mathrm{pg} / \mathrm{mL} .{ }^{21} \mathrm{IL}-10$ is one of the important immunoregulatory cytokines that may affect antitumor immunity and, ultimately, proliferation and resistance to apoptosis. ${ }^{10} \mathrm{Hence}$, it is relatively easy to explain the correlation between IL-10 and B symptoms, between IL-10 and elevated serum LDH, as well as between IL-10 and treatment response. However, it remains unclear why IL-10 levels were also associated with EBV DNA, although some studies found that IL-10 can induce the expression of EBV-encoded latent membrane in NK lymphoma-derived cell lines. ${ }^{25}$

According to the ROC curve analyses, $12.28 \mathrm{pg} / \mathrm{mL}$ was an optimal cutoff value for distinguishing between different prognoses. Patients with high IL-10 levels ( $\geq 12.28 \mathrm{pg} / \mathrm{mL})$ tended to have lower CR rates $(51.3 \%)$ than those with low IL-10 levels $(<12.28 \mathrm{pg} / \mathrm{mL})(72.9 \%)(P=0.034)$. Survival analysis indicated that the 3-year PFS and OS rates in the high IL-10 level group were both significantly lower than those in the low IL-10 level group ( $72.1 \%$ vs $33.7 \%$ for PFS, $P<0.001 ; 79.1 \%$ vs $44.3 \%$ for OS, $P<0.001$ ). Our multiple factor analysis revealed that pretreatment serum IL-10 level was a significant adverse prognostic factor. The patients were treated with GELOX or P-Gemox chemotherapy regimens in this study. Our previous prospective study showed that there was no statistically significant difference in treatment outcomes for patients receiving any type of asparaginase. ${ }^{17}$ Therefore, two different type of asparaginase regimens would not affect our conclusion that serum IL-10 was a strong predictor of treatment response and prognosis in ENKTL, suggesting a key role for IL-10 in the pathogenesis and progression of this disease. IL-10 is part of a balanced network of cytokines and can be cancer-promoting (immunosuppressive; stimulation of cell proliferation) or cancer-inhibiting (antiangiogenic). Polymorphisms in the IL-10 genetically influence interindividual differences in IL-10 production. ${ }^{26,27}$ The relation between IL-10 production capacity and the IL-10 single nucleotide polymorphisms have been reported. ${ }^{28}$ The inconsistent roles of IL-10 in tumors may be partly attributed to single nucleotide polymorphisms.

The mechanisms underlying the relationship between elevated serum IL-10 levels and poor prognosis in ENKTL are not clear. However, several potential explanations have been proposed. Besides its action as a regulation factor of host immunity, IL-10 is one of the growth factor of lymphoma cells. Gravisaco et al suggested that IL-10 is one of the key regulators of in vivo growth of murine T-cell lymphoma cells..$^{29}$ In addition, IL-10 was shown to support and enhance the tumorigenicity of T-cell lymphoma through autocrine modes of action. ${ }^{14}$ Recent studies show that IL-10 specifically activates the JAK/STAT pathway and upregulates c-myc expression in DLBCL cells. ${ }^{21}$ Further, DLBCL cell apoptosis 
induced by JAK2 inhibition was dependent on inhibition of autocrine IL-10 and c-myc expression and independent of Bcl-2 family expression. ${ }^{21}$ Further studies, however, are needed to elucidate the cellular mechanisms of IL-10mediated signaling in NK/T-cell lymphoma.

Clinically, two major clinical prognostic models are applied in NK/T-cell lymphoma: IPI and KPI. In the present study, the univariate analysis showed that the two models were highly prognostic. However, distribution of patients within risk groups based on IPI and KPI scores is unbalanced (as shown in Table 1). Moreover, these two prognostic models failed to differentiate patients with different outcomes in the low-risk group. Serum IL-10 level can divide the patients with IPI or KPI scores of $0-1$ into two subgroups with significant differences in PFS and OS (Figure 3). Therefore, we aimed to develop a novel prognostic model for ENKTL that includes serum IL-10 level. The prognostic value of the new prognostic model is superior to the IPI and KPI model.

In conclusion, this is the first study that confirms the close relationship of IL-10 with several clinical features of ENKTL, including B symptoms, elevated LDH levels, etc. Serum IL-10, which can be easily measured in clinical practice, may be a significant independent prognostic factor for this disease. Compared with previous studies, patients in the present study were uniformly treated with asparaginase-based chemotherapy. These results suggest a role for IL-10 in the pathogenesis of ENKTL and offer new insight into potential therapeutic strategies. Further studies of serum IL-10 are needed to define its role as a prognostic and predictive factor in future Phase III trials in ENKTL.

\section{Acknowledgments}

The authors would like to thank the patients and their families and all the investigators, including the physicians, nurses, and laboratory technicians in this study. This study was supported by the following funds: National Natural Science Foundation of China (contract/grant number: 81272620); and Medical Research Foundation of Guangdong Province (contract/grant number: A2015008).

\section{Disclosure}

The authors report no conflicts of interest in this work.

\section{References}

1. Au WY, Weisenburger DD, Intragumtornchai T, et al. Clinical differences between nasal and extranasal natural killer/T-cell lymphoma: a study of 136 cases from the International Peripheral T-Cell Lymphoma Project. Blood. 2009;113(17):3931-3937.
2. Lee J, Suh C, Park YH, et al. Extranodal natural killer T-cell lymphoma, nasal-type: a prognostic model from a retrospective multicenter study. J Clin Oncol. 2006;24(4):612-618.

3. Sun J, Yang Q, Lu Z, et al. Distribution of lymphoid neoplasms in China: analysis of 4,638 cases according to the World Health Organization classification. Am J Clin Pathol. 2012;138(3):429-434.

4. Wang L, Xia ZJ, Huang HQ, Lu Y, Zhang YJ. Cyclophosphamide, doxorubicin, vincristine, and prednisone (CHOP) in the treatment of stage IE/IIE extranodal natural killer/T cell lymphoma, nasal type: 13-year follow-up in 135 patients. Int $J$ Hematol. 2012;96(5):617-623.

5. Kwong YL, Kim WS, Lim ST, et al. SMILE for natural killer/T-cell lymphoma: analysis of safety and efficacy from the Asia Lymphoma Study Group. Blood. 2012;120(15):2973-2980.

6. Wang H, Wuxiao ZJ, Zhu J, et al. Comparison of gemcitabine, oxaliplatin and L-asparaginase and etoposide, vincristine, doxorubicin, cyclophosphamide and prednisone as first-line chemotherapy in patients with stage IE to IIE extranodal natural killer/T-cell lymphoma: a multicenter retrospective study. Leuk Lymphoma. 2015;56(4):971-977.

7. Suzuki R, Yamaguchi M, Izutsu K, et al. Prospective measurement of Epstein-Barr virus-DNA in plasma and peripheral blood mononuclear cells of extranodal NK/T-cell lymphoma, nasal type. Blood. 2011;118(23):6018-6022.

8. Yamazaki E, Tomita N, Koyama S, et al. Serum ferritin level is prognostic of patient outcome in extranodal NK/T cell lymphoma, nasal type. Med Oncol. 2014;31(9):149.

9. Wang L, Liao DZ, Zhang J, Xia ZJ, Peng XW, Lu Y. Clinical significance of serum soluble interleukin-2 receptor- $\alpha$ in extranodal natural killer/T-cell lymphoma (ENKTL): a predictive biomarker for treatment efficacy and valuable prognostic factor. Med Oncol. 2013;30(4):723.

10. Moore KW, de Waal Malefyt R, Coffman RL, O'Garra A. Interleukin-10 and the interleukin-10 receptor. Annu Rev Immunol. 2001;19: 683-765.

11. Howard M, O’Garra A, Ishida H, de Waal Malefyt R, de Vries J. Biological properties of interleukin 10. J Clin Immunol. 1992;12(4):239-247.

12. Holland G, Zlotnik A. Interleukin-10 and cancer. Cancer Invest. 1993; 11(6):751-758.

13. Lee JJ, Kim DH, Lee NY, et al. Interleukin-10 gene polymorphism influences the prognosis of T-cell non-Hodgkin lymphomas. $\mathrm{Br} \mathrm{J}$ Haematol. 2007;137(4):329-336.

14. Hassuneh MR, Nagarkatti M, Nagarkatti PS. Role of interleukin-10 in the regulation of tumorigenicity of a $\mathrm{T}$ cell lymphoma. Leuk Lymphoma. 2013;54(4):827-834.

15. Danoch H, Kalechman Y, Albeck M, Longo DL, Sredni B. Sensitizing B- and T-cell Lymphoma Cells to Paclitaxel/Abraxane-Induced Death by AS101 via Inhibition of the VLA-4-IL10-Survivin Axis. Mol Cancer Res. 2015;13(3):411-422.

16. Swerdlow SH, Campo E, Harris NL, Jaffe ES, Pileri SA, et al. WHO Classification of Tumours of Haematopoietic and Lymphoid Tissues, 4th Edition. Lyon, France: International Agency for Research on Cancer; 2008.

17. Wang L, Wang ZH, Chen XQ, et al. First-line combination of gemcitabine, oxaliplatin, and L-asparaginase (GELOX) followed by involvedfield radiation therapy for patients with stage IE/IIE extranodal natural killer/T-cell lymphoma. Cancer. 2013;119(2):348-355.

18. Cheson BD, Horning SJ, Coiffier B, et al. Report of an international workshop to standardize response criteria for non-Hodgkin's lymphomas. NCI Sponsored International Working Group. J Clin Oncol. 1999;17(4): 1244.

19. Lech-Maranda E, Baseggio L, Bienvenu J, et al. Interleukin-10 gene promoter polymorphisms influence the clinical outcome of diffuse large B-cell lymphoma. Blood. 2004;103(9):3529-3534.

20. Schoof N, Franklin J, Fürst R, et al. Interleukin-10 gene polymorphisms are associated with freedom from treatment failure for patients with Hodgkin lymphoma. Oncologist. 2013;18(1):80-89.

21. Gupta M, Han JJ, Stenson M, et al. Elevated serum IL-10 levels in diffuse large B-cell lymphoma: a mechanism of aberrant JAK2 activation. Blood. 2012;119(12):2844-2853. 
22. Visco C, Vassilakopoulos TP, Kliche KO, et al. Elevated serum levels of IL-10 are associated with inferior progression-free survival in patients with Hodgkin's disease treated with radiotherapy. Leuk Lymphoma. 2004;45(10):2085-2092.

23. Wang L, Wang WD, Xia ZJ, Zhang YJ, Xiang J, Lu Y. Combination of gemcitabine, L-asparaginase, and oxaliplatin (GELOX) is superior to EPOCH or CHOP in the treatment of patients with stage IE/IIE extranodal natural killer/T cell lymphoma: a retrospective study in a cohort of 227 patients with long-term follow-up. Med Oncol. 2014;31(3):860.

24. Shen L, Chiang AK, Liu WP, Li GD, Liang RH, Srivastava G. Expression of HLA class I, beta(2)-microglobulin, TAP1 and IL-10 in Epstein-Barr virus-associated nasal NK/T-cell lymphoma: Implications for tumor immune escape mechanism. Int J Cancer. 2001;92(5):692-696.

25. Kis LL, Takahara M, Nagy N, Klein G, Klein E. IL-10 can induce the expression of EBV-encoded latent membrane protein-1 (LMP-1) in the absence of EBNA-2 in B lymphocytes and in Burkitt lymphoma- and NK lymphoma-derived cell lines. Blood. 2006;107(7):2928-2935.
26. Turner DM, Williams DM, Sankaran D, Lazarus M, Sinnott PJ, Hutchinson IV. An investigation of polymorphism in the interleukin-10 gene promoter. Eur J Immunogenet. 1997;24(1):1-8.

27. Mormann M, Rieth H, Hua TD, et al. Mosaics of gene variations in the Interleukin-10 gene promoter affect interleukin-10 production depending on the stimulation used. Genes Immun. 2004;5(4):246-255.

28. Gibson AW, Edberg JC, Wu J, Westendorp RG, Huizinga TW, Kimberly RP. Novel single nucleotide polymorphisms in the distal IL-10 promoter affect IL-10 production and enhance the risk of systemic lupus erythematosus. J Immunol. 2001;166(6):3915-3922.

29. Gravisaco MJ, Mongini C, Alvarez E, et al. IL-2, IL-10, IL-15 and TNF are key regulators of murine T-cell lymphoma growth. Int J Mol Med. 2003;12(4):627-632. 


\section{Supplementary material}

Table SI The comparison of clinicopathological features between the GELOX and P-Gemox groups

\begin{tabular}{|c|c|c|c|}
\hline Characteristics & GELOX number of patients (\%) & P-Gemox number of patients (\%) & $P$-value \\
\hline Age, years & & & 1.000 \\
\hline$\leq 60$ & $23(82.1)$ & $56(80.0)$ & \\
\hline$>60$ & $5(17.9)$ & $14(20.0)$ & \\
\hline Sex & & & 0.817 \\
\hline Male & $19(67.9)$ & $45(64.3)$ & \\
\hline Female & $9(32.1)$ & $25(35.7)$ & \\
\hline ECOG PS & & & 0.465 \\
\hline $0-1$ & $24(85.7)$ & $64(91.4)$ & \\
\hline$\geq 2$ & $4(14.3)$ & $6(8.6)$ & \\
\hline B symptoms & & & 0.502 \\
\hline Absent & $15(53.6)$ & $43(61.4)$ & \\
\hline Present & $13(46.4)$ & $27(38.6)$ & \\
\hline Serum LDH & & & 0.628 \\
\hline Normal & $18(64.3)$ & $50(71.4)$ & \\
\hline More than normal & $10(35.7)$ & $20(28.6)$ & \\
\hline EBV DNA & & & 0.826 \\
\hline$<7,650$ & $14(50.0)$ & $37(52.9)$ & \\
\hline$\geq 7,650$ & $14(50.0)$ & $33(47.1)$ & \\
\hline Ferritin levels & & & 0.823 \\
\hline$\leq 315 \mathrm{ng} / \mathrm{mL}$ & 13 & 36 & \\
\hline$>315 \mathrm{ng} / \mathrm{mL}$ & 15 & 34 & \\
\hline sIL2R levels & & & 0.503 \\
\hline$\leq 2,650 \mathrm{ng} / \mathrm{L}$ & 16 & 33 & \\
\hline$>2,650 \mathrm{ng} / \mathrm{L}$ & 12 & 37 & \\
\hline LN involvement & & & 0.506 \\
\hline Absent & $12(42.9)$ & $36(51.4)$ & \\
\hline Present & $16(57.1)$ & $34(48.6)$ & \\
\hline Ann Arbor stage & & & 0.594 \\
\hline $\mid / / I$ & $21(75.0)$ & $56(80.0)$ & \\
\hline III/IV & $7(25.0)$ & $14(20.0)$ & \\
\hline IPI score & & & 1.000 \\
\hline $0-1$ & $22(78.6)$ & $54(77.1)$ & \\
\hline $2-5$ & $6(21.4)$ & $16(22.9)$ & \\
\hline KPI score & & & 0.117 \\
\hline $0-1$ & $13(46.4)$ & $45(64.3)$ & \\
\hline $2-4$ & $15(53.6)$ & $25(35.7)$ & \\
\hline
\end{tabular}

Abbreviations: EBV DNA, Epstein-Barr virus DNA; ECOG PS, Eastern Cooperative Oncology Group performance status; GELOX, gemcitabine, oxaliplatin, and L-asparaginase; IPI, International Prognostic Index; KPI, Korean Prognostic Index; LDH, lactate dehydrogenase; LN, lymph node; P-Gemox, gemcitabine, oxaliplatin, and pegaspargase; sIL2R, soluble interleukin-2 receptor.

\section{Publish your work in this journal}

OncoTargets and Therapy is an international, peer-reviewed, open access journal focusing on the pathological basis of all cancers, potential targets for therapy and treatment protocols employed to improve the management of cancer patients. The journal also focuses on the impact of management programs and new therapeutic agents and protocols on patient perspectives such as quality of life, adherence and satisfaction. The manuscript management system is completely online and includes a very quick and fair peer-review system, which is all easy to use. Visit http://www.dovepress.com/testimonials.php to read real quotes from published authors.

Submit your manuscript here: http://www.dovepress.com/oncotargets-and-therapy-journal 